\title{
Cibercultura: ascensão e declínio de uma palavra quase mágica
}

\author{
Erick Felinto
}

\section{Resumo}

"Words are magic"

(Walt Whitman)

A partir de uma análise da bibliografia crítica dos

estudos sobre a cultura digital, adota-se como premissa

a tese de um progressivo declínio do termo cibercultura

nos últimos anos. Extremamente carregada de

sentidos e de uma história que possivelmente já não

correspondem ao atual estado da cultura tecnológica,

a palavra teria perdido seu encanto tanto no horizonte

das representações "populares" quanto no domínio

das apreensões acadêmicas. Como substitutivo da

cibercultura, propõe-se a expressão "estudos de mídia"

como definidora não de uma disciplina, mas antes

de um campo de investigação demarcado por três

grandes eixos teóricos: materialidades, medialidades e

temporalidades.

\section{Palavras-chave:}

Cibercultura. Tecnologias Digitais. Epistemologia.

Terminologia. Estudos de Midia.

Erick Felinto | erickfelinto@gmail.com

Doutor em Literatura Comparada e professor do Programa de PósGraduação em Comunicação da Universidade doEstado do Rio de Janeiro (UERJ). 
frente às incertezas do devir. Nesse sentido, as proposições de Blumenberg podem constituir um interessante modelo crítico para analisar não apenas o vasto conjunto de discursos (míticos) que envolvem a cibercultura, mas também a própria palavra que os subsume.

Sem dúvida, a multiplicidade de sentidos e fenômenos abarcados pelo termo "cibercultura" encontra uma significante convergência em sua função didática e em sua tranquilizadora reafirmação de um progresso constante. A face mais popular da cibercultura, aquilo que Sidney Eve-Matrix (2006) chama de "cyberpop", tem como atribuição mediar a relação entre os públicos heterogêneos e a assustadora complexidade do mundo tecnocientífico. É a partir dessa perspectiva que podemos dizer que a ficção científica, as fábulas cinematográficas e as propagandas dos produtos tecnológicos user-friendly cumprem, por vezes, papéis convergentes. Elas nos oferecem certas representações culturais da tecnologia ao alcance do homem comum. 0 mundo hermético dos especialistas e iniciados se descortina, assim, diante do simples usuário - ainda que, necessariamente, em uma forma simplificada e massificante. Ao mesmo tempo, no núcleo mais profundo desses discursos, encontramos narrativas que repetem o mito moderno do progresso permanente e do bem estar humano por meio do avanço tecnológico. 0 futuro, com todas as incertezas que poderá trazer, torna-se menos inquietante. A temporalidade linear do progresso, a domesticação das diferenças, a repetição de formas mentais já conhecidas funcionam, assim, como elementos tranquilizadores. E desse modo, há muito na cibercultura que é bem menos "novo" do que pode parecer à primeira vista. Talvez seja esse um dos fatores responsáveis pelo declínio da popularidade do termo na literatura especializada. Para algumas pessoas, 0 sentido de novidade da cibercultura já não é tão pregnante como costumava ser. Não é um dado preciso, mas talvez funcione pelo menos como indicador: 0 site da Amazon nos apresenta 34 obras com títulos que contêm a palavra "cibercultura" publicados entre os anos de 2000 e 2004, mas apenas 21 entre 2005 e 2009. Em 2010, contam-se apenas quatro. ${ }^{1} 0$ fato é que, a exemplo de Lev Manovich (2009), alguns estudiosos do assunto já começam agora a renegar 0 termo.

Mas mesmo que o termo cibercultura continue gozando de alguma popularidade em certos meios, ele parece menos apto a definir um domínio epistemológico que outras expressões recentemente favorecidas pela crítica, como new media studies ou internet studies. É curioso que na coletânea recentemente organizada por Steve Jones em 2006, Critical Cyberculture Studies, a palavra se apresente no título, mas desapareça completamente da introdução, para ser substituída por "estudos de internet". E, num 
movimento que vários outros trabalhos repetem

- por exemplo, Gane e Beer, 2008 -, Jones inicia sua discussão perguntando se internet studies deve ser entendido como um campo ou disciplina. ${ }^{2}$

Face a essa situação, caberia perguntar:

estaríamos enfrentando, após apenas pouco mais de 30 anos de seu nascimento, uma prematura morte da cibercultura? Mas a pergunta merece um desdobramento complexificador. Menos que uma desaparição das questões motivadas pelas novas mídias digitais, cuja popularidade entre pesquisadores e instituições acadêmicas é inegável, talvez se trate antes de um esgotamento terminológico. Para Siegfried Zielinski (informação verbal),${ }^{3}$ por exemplo, o termo cibercultura já tem, hoje, um sabor levemente antiquado. Na Alemanha, acredita ele, experimentou relativo êxito entre fins dos anos 1980 e meados da década de 1990, para então cair no esquecimento quase que total. Por outro lado, nunca se discutiu tanto na Alemanha sobre 0 tema da mediação tecnológica (especialmente em relação aos "novos meios") quanto hoje. Isso indica que algo no termo "cibercultura" pode já não responder aos anseios de nosso momento histórico. Naturalmente, poder-se-ia enumerar um conjunto de diferentes razões para isso. Contudo, pretendo desenvolver meu argumento aqui com base numa proposição específica. Minha hipótese é de que o termo "cibercultura" marcou, em momento determinado da história cultural-tecnológica do Ocidente, um período fortemente dominado pelo tema da "automação". Quase 50 anos após a primeira utilização da palavra, em 1963 - pelo menos segundo o Oxford English Dictionary citado pela Wikipedia - , a questão central das novas mídias já não é a transferência do labor humano para as máquinas, mas sim a expansão do potencial criativo do homem através da tecnologias de informação e comunicação.

De fato, o competente verbete cyberculture [2004?] da Wikipedia atribui aos primeiros usos do termo, marcados por esse sentido da passividade humana frente à máquina, as origens da definição consagrada até aproximadamente 1995. 0 sentido mais evidente de cibercultura era, então, 0 de nomear as "[...] condições sociais originadas com a automação e computadorização". ${ }^{4}$ Sabemos que a complexa história da palavra e da gênese da noção de cibercultura está ligada à ideia de controle, expresso já no prefixo "ciber" decalcado do grego kybernetes ("governante", "navegador"). Esse é 0 sentido central que Norbert Wiener buscará explorar quando cunha

2 Uma questão, como assinala Jones, replicada pela própria Comunicação, cujo estatuto, entre campo e disciplina, nunca foi inteiramente clarificado. Na parte final do artigo, retomarei a discussão de Jones.

Entrevista pessoal concedida ao autor em 21 de fevereiro de 2011.

Definição do Oxford English Dictionary segundo a Wikipedia [2004?]. 0 primeiro uso registrado, de 1963, encontrava-se em H. M. Milton: "In the era of cyberculture, all the plows pull themselves and the fried chickens fly right onto our plates" (Na era da cibercultura, todos os arados se puxam sozinhos e as galinhas fritas voam diretamente para nossos pratos). 
o termo "cibernética". Como ele deixa claro na introdução de sua obra The Human Use of

Human Beings: Cybernetics and Society:

Quando me comunico com outra pessoa, eu Ihe transmito uma mensagem, e quando ela se comunica de volta a mim, devolve-me uma mensagem relacionada que contém informação primariamente acessível a ela e não a mim. Quando controlo as ações de outra pessoa, comunico a ela uma mensagem, e ainda que essa mensagem esteja no modo imperativo, a técnica de comunicação não difere daquela de uma mensagem de facto (WIENER, 1989, p. 16, tradução nossa). ${ }^{5}$

A perspectiva sistêmica adotada por Wiener, assim como por Shannon e outros partidários da cibernética, implicava a desconsideração dos possíveis sentidos das mensagens. 0 que importava, realmente, era a eficácia na transmissão da mesma, a eliminação de ruídos potenciais, 0 bom funcionamento dos sistemas. Nessa perspectiva, seres humanos e máquinas não seriam essencialmente diferentes. A questão central, portanto, tinha a ver com estudar as melhores formas de acoplagem entre sistemas orgânicos e inorgânicos. Não por acaso, 0 problema inicial de Wiener em suas pesquisas no Radiation Lab do MIT era o perfeito ajustamento dos operadores de metralhadoras em aviões de combate aéreo ao complexo maquinário com que tinham de operar (Cf. TURNER, 2006). Essa relação entre comunicação, sistemas de informação e máquinas de guerra constitui um caso perfeito para os historiadores da mídia que, como Virilio (2009) e Kittler (1986), enxergam a trajetória do desenvolvimento tecnológico como uma história eminentemente militar. E não seria de modo algum paranóico lembrar como as origens da cibercultura, especialmente no que se refere à internet, se entrelaçavam com projetos e objetivos de natureza militar.

É curioso, porém, que poucas historiografias da cibercultura tenham se empenhado em dissecar cuidadosamente esse aspecto sombrio de suas origens. Ao descrever o que chama de early cyberculture - período que vai dos anos 60 até meados dos anos 1990 -, Jacub Macek (2005) não toca nessa questão, preferindo concentrar-se nas subculturas hacker e no lento processo de passagem do fenômeno das margens culturais ao mainstream. É Fred Turner (2006) quem nos apresenta com riqueza de detalhes as profundas contradições que marcam o desenvolvimento histórico da cibercultura, caracterizado por uma combinação paradoxal entre forças libertárias e impulsos de controle. Mas mesmo a tradicional narrativa das origens ciberculturais nas comunidades "libertárias" de tecnófilos nos oferecem algumas pistas interessantes. Lembremos: tratavam-se, e em boa medida ainda 0 são, de subculturas profundamente "falocêntricas". 0 hacker ideal das mitologias ciberculturais é 0 adolescente de sexo masculino, perturbado continuamente por sua inadaptação social e que frequentemente 
desenvolve tendências agressivas. Um dos filmes mais populares sobre a incipiente cultura informática, vale assinalar, foi War Games (1983), onde um jovem hacker penetra um sistema computadorizado militar e quase provoca a terceira guerra mundial, pensando tratar-se de um mero jogo de computador. E que dizer do clássico Tron (1982), no qual um hacker invade o próprio interior do "cosmos" computadorizado, ali descobrindo um mundo onde programas travam combates de vida e morte em arenas de gladiadores? Automação, controle e conflito compunham temas correntes nesse período inicial da cibercultura.

Alguns anos depois do início da empreitada cibernética, operando entre 0 tensionamento e a admiração pelo legado de Wiener, 0 pensamento de Gilbert Simondon irá trazer uma contribuição inovadora à filosofia da técnica e ao tema do automatismo. Simondon se colocará radicalmente contra a noção da máquina que trabalha autonomicamente sem a necessidade de intervenção humana. Para ele, robôs, máquinas inteligentes e todos os tipos de autômatos constituem fantasias da ficção científica que prestam um desserviço à saúde de nossas relações com os aparatos técnicos:

0 verdadeiro aperfeiçoamento das máquinas, aquele do qual se pode dizer que eleva 0 grau da tecnicidade, corresponde não a um incremento do automatismo, mas, pelo contrário, ao fato de que 0 funcionamento de uma máquina guarda uma certa margem de interpretação (SIMONDON, 1989, p. 11, tradução nossa). ${ }^{6}$

É essa marge d'indétermination, fora da esfera do controle, que permite, por um lado, preservar certo potencial criativo e de inovação do aparato técnico e, por outro, a contínua intervenção do agente humano. Para Simondon, é apenas através da relação direta com o homem como direcionador da máquina que 0 desenvolvimento tecnológico pode verdadeiramente se processar. Uma pequena passagem na mesma página parece não ter chamado muito a atenção dos estudiosos de Simondon, mas revela-se bastante interessante quando pensada a partir de uma perspectiva contemporânea: segundo o autor, os idólatras do técnica imaginam que 0 aumento progressivo do maquinismo teria como resultado final uma "interconexão" de todas as máquinas entre si, de modo a constituir uma "máquina das máquinas". Sob certo ponto de vista, poderíamos dizer que essa super-máquina já existe hoje, e é a internet.

Todavia, a internet é a prova mais cabal da operação criativa do maquinismo através da intervenção humana. Não obstante 0 grande interesse do imaginário cibercultural pelo tema da inteligência artificial, a questão das relações humanas com os objetos tecnológicos tem constituído um dos focos privilegiados de atenção das interpretações sobre a cultura digital. No lugar de uma relação de dominância do homem para com a máquina (ou vice-versa), 
poderíamos dizer que as apreensões mais recentes apresentam um acento simondoniano, ao promover uma visão do encontro entre o humano e 0 tecnológico nos moldes de uma parceria produtiva. E, paralelamente, uma análise do tema da corporalidade revela uma significativa mudança de atitude no que se refere ao papel das materialidades no contexto da cibercultura. Se a retórica da early cyberculture foi caracterizada pelos sonhos de desmaterialização e virtualização, muitas leituras mais recentes preferem destacar a importância do corpo, do toque e das sensações em nossa interação com as novas mídias. De fato, a importância desses temas tem crescido de forma tão determinante que podemos dizer que constituem um dos eixos privilegiados de compreensão do fenômeno tecnológico na contemporaneidade, ao lado das questões da temporalidade e da medialidade. Uma obra como Media Ecologies: Materialist Energies in Art and Technoculture, dá testemunho claro desse movimento. Como explica Matthew Fuller (2005, p. 2, tradução nossa): “[...] crucial a uma tal abordagem [a adotada pela obra] é um entendimento de que uma atenção à materialidade é mais frutífera onde ela é freqüentemente julgada como irrelevante, nos domínios ‘imateriais' da mídia eletrônica."

No mundo antisséptico das fantasias descorporificantes, o corpo e a realidade material eram identificados como a "sujeira" da qual o ciberespaço iria nos libertar. A metáfora da internet como Nova Jerusalém Celestial, tão competentemente estudada por Wertheim (1999), repousa na ideia de habitar um mundo livre das imperfeições da matéria e dos corpos. Essa retórica religiosa, que, aliás, ainda compõe um elemento importante do imaginário cibercultural, identifica o corpo (e suas paixões) como entidade que deve ser controlada e purificada. Como sugiro em A Religião das Máquinas (2005), entre pelo menos os anos de 1980 e meados de 1990, parte significativa das interpretações teóricas sobre a cibercultura encontrava-se eivada de noções mítico-religiosas dessa natureza. Como seria de se esperar, porém, a literatura acadêmica parece hoje descolar-se, progressivamente, do tipo de discursividade mitológica, utópica ou projetiva característica das representações mais populares da cibercultura. Nesse sentido, é interessante comparar algumas obras produzidas no período da early cyberculture com produções mais contemporâneas. Se uma coletânea de textos "clássica", como Cyberspace: First Steps (1992) prodigaliza uso de metáforas, projeções futuristas e representações utópicas sobre as mídias digitais, muitos trabalhos mais recentes, como Digital Contagions (2007) ou From Counterculture to Cyberculture (2006) se dedicam a examinar criticamente os discursos mitologizantes da cibercultura. De fato, ao realizarmos um recorte analítico por data de publicação - tendo com marco temporal uma comparação entre obras produzidas antes e depois do ano de 2000 -, percebemos na literatura acadêmica um acentuado decréscimo no uso de certas metáforas 
tradicionais, como "cidade celestial" (internet),

"corpo angelical" (internauta) ou "labirintos

digitais" (hipertexto). Sintomática do atual

momento histórico - de possivelmente relativa

maturidade no que se refere à apreensão dos

impactos das tecnologias digitais -, a coletânea

crítica de Hassan e Thomas, The New Media

Theory Reader, explicita uma preocupação em

evitar os entusiasmos excessivos. Mais que isso,

rompe com a retórica da revolução radical e da

ruptura com o passado que caracterizou porção

relevante da literatura sobre meios digitais em

momento anterior:

Ainda que 0 termo novos meios seja, ele próprio, um novo termo, datando de menos de 50 anos atrás, as questões que ele levanta não são novas, e um entendimento das transformações contemporâneas promovidas por celulares e pela internet se beneficia de uma conscientização sobre as 'novas tecnologias' anteriores, tais como a imprensa, o rádio e o telégrafo. 0 s novos meios, de uma forma ou de outra, têm estado conosco desde há séculos (HASSAN; THOMAS, 2006, p. Xviii, tradução nossa).

Aliás, voltando ao problema da terminologia, alguns exercícios de investigação bibliográfica indicam que a expressão new media pode estar mesmo tomando o lugar da palavra cibercultura. Na produção em língua inglesa, o número de títulos de obras contendo a palavra cyberculture parece cair progressivamente, ou pelo menos manter-se estável, ao passo que o uso do termo "new media" cresce ano a ano. De 96 títulos em 2006, passamos a 142 em 2008 e a 157 em
$2010 .^{7}$ Podemos ter a impressão de que a segunda palavra é mais ampla que a primeira, já que cibercultura apresenta, no interior próprio termo, um componente cultural específico que o primeiro não sugere, pelo menos explicitamente. Todavia, a bibliografia acadêmica trata nitidamente os new media ou internet studies como campos de investigação amplos e com forte foco cultural. A partir da proposta de definir seis conceitos-chave para 0 estudo das novas mídias, o "reader" de Gane e Beer (2008, p. 1), por exemplo, se preocupa continuamente em destacar seu interesse pelos aspectos sociais e culturais:

[...] 0 objetivo é identificar conceitos para a análise de formas de vida social e cultura altamente tecnologizadas, e investigar como esses conceitos podem ser operacionalizados na qualidade de chaves para enfrentar problemas e barreiras encontradas em tal pesquisa.(tradução nossa)

Por outro lado, é curioso observar que cibercultura vem se apresentando, quase que exclusivamente, em obras de cunho acadêmico, enquanto new media desfruta de alta popularidade no domínio dos manuais técnicos, os conhecidos how to. Isso talvez signifique que, também no horizonte da apreensão popular, das representações culturais do senso comum, cibercultura começa a perder seu apelo mágico. E a ubiquidade que antes estava implicada naquela palavra - por vezes tinha-se a impressão de que a cibercultura abarcava a totalidade do campo cultural - agora se transfere para o domínio dos new media. 
A incrível variedade de temas que podem ser associados a tal termo vai desde os estudos medievais (Geoffrey Chaucer hath a blog: Medieval Studies and New Media, 2010) ao cinema indiano de Bollywood (Bollywood in the Age of New Media: the Geo-Televisual Aesthetic, 2010). Desse modo, não custa acreditar que a expressão new media também corre o risco de se converter em uma mot de passe. A "magia" desse tipo de vocábulo é de dupla natureza: por um lado sua esfera de aplicabilidade se estende a quase todo o universo, sem, contudo, nunca oferecer um sentido preciso e localizável; por outro, invoca automaticamente uma sensação acrítica de sedução radical. Tudo que tem a ver com as novas mídias é automaticamente bom, bonito e atual. Como o Midas das narrativas mitológicas, 0 usuário da expressão new media converteria em ouro tudo o que viesse a tocar.

Nesse sentido, valeria a pena insistir numa consideração mais crítica do qualificativo "novo". Como assinalei anteriormente, acredito que um dos eixos privilegiados de compreensão do fenômeno tecnológico na contemporaneidade é o tema da temporalidade. Em outras palavras, em anos recentes os estudos de mídia têm demonstrado uma tendência interessante de compensação da tradicional retórica da ruptura através da investigação histórico-cultural das mídias. A popularidade de paradigmas de pesquisa como a história da mídia alemã (Mediengeschichte) ou da "arqueologia da mídia" (herdeira direta da primeira) vem oferecendo um contraponto interessante ao valor que a cultura tecnológica, e em especial a cibercultura, sempre conferiu ao índice de "novidade". Em vez de enxergar o presente como um eterno início e 0 futuro como promessa a se realizar, os estudos críticos de historiografia da mídia pretendem relativizar a sentido do novo ao confrontá-lo com momentos passados. Não se trata apenas de revelar o que existe de antigo naquilo que se apresenta como novo, mas também de encontrar o novo no antigo (ZIELINSKI, 2002). 0 problema das historiografias triunfalistas - que na verdade simplesmente acompanham a tendência dominante do desenvolvimento tecnológico industrial - é sua afirmação reducionista de modelos hegemônicos, de paradigmas excludentes. Nesse sentido, uma tarefa premente da arqueologia da mídia seria buscar, em outras temporalidades e em outros territórios geográficos, modelos heteronômicos, proposições marginais, experiências minoritárias.

Em um dos mais competentes exemplos de exercício "midio-arqueológico" nos últimos anos, Jussi Parikka (2007, p. 4) oferece descrições precisas das metas desse novo paradigma de pesquisa. Para ele, trata-se de uma proposta "comprometida com a busca das condições de existência dos fenômenos culturais e 0 intercâmbio entre continuidades e descontinuidades". Mais que isso,

[...] a arqueologia da mídia deve não apenas traçar 0 entendimento majoritário dos discursos e dispositivos da cultura digital, mas também 
procurar acompanhar os desvios e experimentos que permanecem virtuais e, contudo, reais, nas sombras da atualidade do entendimento hegemônico (PARIKKA, 2007, p. 24).

A arqueologia dos vírus de computador de Parikka põe em evidência um elemento dos processos tecnológicos que as narrativas triunfalistas precisamente sempre tentaram suprimir: 0 ruído. Liberando o ruído de sua valoração unicamente negativa, como obstáculo da atividade comunicacional, Parikka demonstra cabalmente seu papel produtivo e sua importância como elemento em nossa história cultural recente e na lógica do capitalismo tardio. ${ }^{8}$

Mas mesmo saindo do campo mais específico de uma "arqueologia da mídia", é possível dizer que abordagens históricas e comparativistas têm caracterizado boa parte da produção no campo dos estudos de mídia. Exemplos dessa espécie de empresa téorica não têm faltado: Manovich (2001), Gitelman (2004), Bolter e Grusin (1999), Crary (2000), Martin (1991), Siegert (2003) e muitos outros. Toda esse interesse pelas investigações históricas talvez sirva também para nos ensinar outra lição: qualquer tentativa de análise do fenômeno das novas mídias deve começar pela relativização do conceito de "novo". Distinções radicais entre as "novas" e as "antigas" mídias não fazem sentido. Isso não quer dizer que o momento presente e as formas tecnológicas que lhe são correlatas não têm nada de singular. Afirmar isso seria negar o próprio movimento histórico. Todavia, precisamos entender o que permanece de anterior e analógico nas mídias digitais, assim como aquilo que as mídias analógicas anunciam e antecipam para o futuro (ou seja, nosso presente). ${ }^{9}$ Combater a retórica da ruptura radical significa, portanto, lançar um olhar mais amplo para os processos histórico-tecnológicos; buscar uma perspectiva do "tempo profundo das mídias" (Tiefenzeit der Medien), como sugere Zielinski (2002).

\section{Conclusão: materialidades, medialidades, temporalidades}

A palavra cibercultura vem cumprindo, desde pelo menos 1980, uma curiosa dupla função. Por um lado, ela designa certo estado de coisas ligado à experiência contemporânea. A cibercultura constitui o conjunto das "questões culturais relacionadas aos 'ciber-tópicos', por exemplo, a cibernética, a computadorização, a revolução digital, a ciborguização do corpo humano, etc." (MACEK, 2005, p. 1). Por outro, ela nomeia o saber teórico que se dedica a investigar criticamente esse mesmo conjunto de fenômenos. Ambos os sentidos são igualmente amplos e com fronteiras extremamente maleáveis. Mas pode ser que a magia do termo cibercultura

Segundo informou-me Parikka, está prestes a ser lançado o que talvez seja a primeira coletânea sistemática dedicada a reunir trabalhos de investigadores no campo da arqueologia da mídia. Na verdade, a obra já aparece na página da Amazon e deve ser lançada em maio deste ano. (Cf. PARIKKA, 2011) 
esteja se esgotando. É verdade que ele encerra um potencial imaginativo interessante. Se muitos mitos ciberculturais colaboram para a manutenção do status quo e inibem um olhar mais crítico da cultura tecnológica, outras narrativas digitais imaginam futuros carregados de potência criadora. Mas o problema de muitos discursos expectantes é visar ao futuro sem explorar suficientemente 0 presente. E é no presente que se concentram, em germe, as heteronomias que poderão oferecer um porvir menos tipificado e totalitário.

Por outro lado, do ponto de vista da constituição de um saber tecnológico, existem indícios de que a expressão "estudos de mídia" deverá institucionalizar-se definitivamente em anos vindouros. Em lugar das "novas mídias", um qualificativo que me parece, em alguma medida enganoso, investigar a "mídia" e a dimensão medial dos fenômenos culturais, pode nos oferecer uma saída da circularidade da retórica da inovação. Na Alemanha, com a Medienwissenschaft (ciência dos meios) ou a Medientheorie (teoria dos meios), parece já se ter consagrado um olhar distribuído por toda a extensão temporal da dinâmica tecnológica. Como já se apontou diversas vezes, toda mídia foi "nova" em certo momento de sua história. Que fique claro: há poucos sinais - e boa parte da bibliografia contemporânea aponta isso - de que seremos capazes de constituir uma disciplina definida e acabada. Com Steve Jones, porém, não penso que isso seja um demérito para o campo dos estudos de mídia. Igualmente não o tem sido para a Comunicação em nosso meio, não obstante as muitas - e, a meu ver, em sua maioria frustradas - tentativas de lhe atribuir um estatuto disciplinar preciso. A flexibilidade oferecida pelo entendimento dos estudos de mídia como um campo nos permitirá reconfigurar continuamente suas fronteiras e problemas. Desse modo, pode ser que a assustadora velocidade das transformações tecnológicas não torne, em futuro próximo, irrelevantes os escritos que produzimos hoje.

Se este texto pode ser traduzido em uma única aposta central, eu diria que ela consiste na crença de que três eixos de investigação irão desempenhar papel vital nos anos por vir. Falar em materialidades, medialidades e temporalidades significa desenhar um esboço de um mapa epistemológico no qual assinalamos os acidentes geológicos para os quais devemos estar mais cuidadosamente atentos. Talvez uma das vantagens desses termos seja 0 de não estarem carregados do mesmo tipo de sentidos ou história(s) que uma palavra como "cibercultura". De certa forma, eles são mais maleáveis, mais abertos, mais flexíveis. Curiosamente, em sua proposta de estruturação de um campo para os estudos de internet, Jones também atentou para o poder do verbo. Buscando apoio em um texto de Joli Jensen, Jones (2006, p. 7) destaca "[...] a importância de ser auto-reflexivo a respeito de como lidamos com a nomeação dos objetos e temas de nosso estudo". Como advertiu Jensen (1993 apud JONES, 2006, p. 7), ao criar mapas e definir, nós "[...] criamos aquilo que 
pretendíamos simplesmente descrever".

A percepção desse papel ativo do investigador é importante inclusive para que não tenhamos nenhuma ilusão quanto à natureza construída da realidade que supostamente observamos. Desse modo, nossas escolhas vocabulares assumem a maior importância. Se talvez seja este 0 momento necessário de nossa despedida da cibercultura, precisamos nos acautelar para não recair em nova infiltração mágica em quaisquer que sejam os nomes que viermos a usar. Se as palavras criam mundos, os nossos pequenos cosmos, à diferença do verbo divino, serão sempre incompletos, falhos e abertos.

\section{Referências}

BASU, Anustup. Bollywood in the age of new media. Edinburgh: Edinburgh University Press, 2010.

BENEDIKT, Michael. Cyberspace: first steps.

Cambridge: MIT Press, 1992.

BLUMENBERG, Hans. Arbeit am Mythos.

Frankfurt: Suhrkamp, 2001.

BOLTER, Jay David; GRUSIN, Richard.

Remediation: understanding new media.

Cambridge: MIT Press, 2002.

BOLZ, Norbert. Theorie der neuen Medien.

Marburg: Raben, 1990.

BRIANT, Brantley J. Geoffrey Chaucer hath a

Blog: medieval studies and new media. New York:
Pallgrave, 2010.

CIBERCULTURE. In: WIKIPEDIA. [2004?]

Disponível em: < http://en.wikipedia.org/wiki/

Cyberculture>

CRARY, Jonathan. Suspensions of perception: attention, spectacle, and modern culture.

Cambridge: MIT Press, 2000.

FULLER, Matthew. Media ecologies: materialist energies in art and culture. Cambridge: The MIT Press, 2005.

GANE, Nicholas; BEER, David. New Media: the key concepts. 0xford: Berg, 2008.

GITELMAN, Lisa. Always already new: media, history and the data of culture. Cambridge: The MIT Press, 2006.

HASSAN, Roberts; THOMAS, Julian (Org.). The new media theory reader. New York: Open University Press, 2006.

JONES, Steve et al. (Org.). Critical cyberculture studies. New York: NYU Press, 2006.

KITTLER, Friedrich. Grammophon, Film, Typewriter. Berlin: Brinkmann \& Bose, 1986.

KLEIN, Ernst. A comprehensive dictionary of the hebrew language for readers of english. Jerusalem: University of Haifa, 1987.

MACEK, Jakub. Defining cyberculture. 2005. Disponível em: < http://macek.czechian.net/ defining_cyberculture.htm > Acesso em: jun. 2006. 
Personal Homepage do Autor.

MANOVICH, Lev. The language of new media.

Cambridge: MIT Press, 2001.

. Cyberculture is an old-fashioned term

[mensagem pessoal], Mensagem recebida por

<erickfelinto@uol.com.br> em 23 jun.2009.

MARTIN, Michèle. Hello Central? Gender,

technology and culture in the formation of

telephone systems. Montreal: McGill University

Press, 1991.

MATRIX, Sidney Eve. Cyberpop: digital lifestyles

and commodity culture. New York: Routledge,

2006.

PARIKKA, Jussi. Digital contagions: a media archaeology of computer viruses. New York: Peter Lang, 2007.

PARIKKA, Jussi; HUHTAMO, Erkki. Media

archaeology: approaches, applications and implications. Los Angeles: University of California Press, 2011.

SIEGERT, Bernhard. Passagen der

digitalen: Zeichenpraktiker der neuzeitlichen

Wissenschaften. Berlin: Bose \& Brinkmann, 2003.

SIMONDON, Gilbert. Du Mode d'Existence des

objets techniques. Paris: Aubier, 1989.

TRON. Direção e roteiro: Steven Lisberger. Elenco:

Jeff Bridges, Bruce Boxleitner and David Warner.

[S.l.]: Walt Disney Productions, 1982. (96 min.),

Son., Color.
TURNER, Fred. From counterculture to

cyberculture. Chicago: University of Chicago

Press, 2006.

VIRILIO, Paul. Guerre et cinéma. Paris: Cahiers

Du Cinema, 2009.

ZIELINSKI, Siegfried. Archäologie der Medien:

zur tiefenzeit des technischen Hörens und Sehens.

Hamburg: Rowohlt, 2002.

WAR Games. Direção: John Badham. Roteiro:

Lawrence Lasker e Walter F. Parkes Elenco:

Matthew Broderick, Ally Sheedy e John Wood. Los

Angeles: MGM, 1983. (114 min.) Son., Color.

WERTHEIM, Margaret. The pearly gates of

cyberspace: a history of space from Dante to the

Internet. New York: W. W. Norton \& Company, 1999.

WIENER, Norbert. The human use of human

beings. London: Free Association Books, 1989. 


\begin{tabular}{|c|c|}
\hline $\begin{array}{l}\text { Ciberculture: rise and decline of an } \\
\text { almost magical word }\end{array}$ & $\begin{array}{l}\text { Cibercultura: ascenso y descenso } \\
\text { de una palabra casi mágica }\end{array}$ \\
\hline $\begin{array}{l}\text { Abstract: } \\
\text { A careful analysis of the critical literature on digital } \\
\text { culture indicates that the word "cyberculture" } \\
\text { has been facing a steady decline in the last few } \\
\text { years. Charged with meanings and a history that } \\
\text { probably no longer correspond to the current state } \\
\text { of technological culture, the word seems to have } \\
\text { lost its appeal, both in the sphere of "popular" } \\
\text { representations as well as in the domain of } \\
\text { academic appraisals. As a substitutive for the term } \\
\text { "cyberculture", "media studies" arises not so much as } \\
\text { a label for a new academic discipline than as a field of } \\
\text { research demarcated by three major theoretical axes: } \\
\text { materialities, medialities and temporalities. } \\
\text { Keywords: } \\
\text { Cyberculture. Digital Technologies. Epistemology. } \\
\text { Terminology. Media Studies. }\end{array}$ & $\begin{array}{l}\text { Resumen: } \\
\text { A partir de un análisis de la bibliografía crítica } \\
\text { de los estudios sobre cultura digital, adoptase } \\
\text { como premisa la tesis de un progresivo declino } \\
\text { del termo cibercultura en los últimos años. } \\
\text { Extremamente cargada de sentidos y de una } \\
\text { historia que posiblemente ya no corresponden al } \\
\text { actual estado de la cultura tecnológica, la palabra } \\
\text { habría perdido su encanto tanto en el horizonte } \\
\text { de las representaciones "populares" como en el } \\
\text { dominio de las evaluaciones académicas. Como } \\
\text { sustitutivo para cibercultura, se propone la } \\
\text { expresión "estudios de medíos" como definidora } \\
\text { no tanto de una disciplina, sino más bien de } \\
\text { un campo de investigación demarcado por } \\
\text { tres grandes ejes teóricos: materialidades, } \\
\text { medialidades e temporalidades. } \\
\text { Palabras clave: } \\
\text { Cibercultura. Tecnologías Digitales. Epistemología. } \\
\text { Terminología. Estudios de Medios. }\end{array}$ \\
\hline
\end{tabular}




\section{Expediente}

A revista E-Compós é a publicação científica em formato eletrônico da Associação Nacional dos Programas de Pós-Graduação em Comunicação (Compós). Lançada em 2004, tem como principal finalidade difundir a produção acadêmica de pesquisadores da área de Comunicação, inseridos em instituições do Brasil e do exterior.

\section{E-COMPÓS I www.e-compos.org.br I E-ISSN 1808-2599}

Revista da Associação Nacional dos Programas de Pós-Graduação em Comunicação.

Brasília, v.14, n.1, jan/abr. 2011

A identificação das edições, a partir de 2008

passa a ser volume anual com três números.

\section{CONSELHO EDITORIAL}

Afonso Albuquerque, Universidade Federal Fluminense, Brasil Alberto Carlos Augusto Klein, Universidade Estadual de Londrina, Brasil Alex Fernando Teixeira Primo, Universidade Federal do Rio Grande do Sul, Brasil Ana Carolina Damboriarena Escosteguy, Pontifícia Universidade Católica do Rio Grande do Sul, Brasil

Ana Gruszynski, Universidade Federal do Rio Grande do Sul, Brasil Ana Silvia Lopes Davi Médola, Universidade Estadual Paulista, Brasil André Luiz Martins Lemos, Universidade Federal da Bahia, Brasil Ângela Freire Prysthon, Universidade Federal de Pernambuco, Brasil Angela Cristina Salgueiro Marques, Faculdade Cásper Líbero (São Paulo), Brasil Antônio Fausto Neto, Universidade do Vale do Rio dos Sinos, Brasil Antonio Carlos Hohlfeldt, Pontifícia Universidade Católica do Rio Grande do Sul, Brasil Antonio Roberto Chiachiri Filho, Faculdade Cásper Líbero, Brasil Arlindo Ribeiro Machado, Universidade de São Paulo, Brasil Arthur Autran Franco de Sá Neto, Universidade Federal de São Carlos, Brasil Benjamim Picado, Universidade Federal Fluminense, Brasil César Geraldo Guimarães, Universidade Federal de Minas Gerais, Brasil Cristiane Freitas Gutfreind, Pontifícia Universidade Católica do Rio Grande do Sul, Brasil Denilson Lopes, Universidade Federal do Rio de Janeiro, Brasil Denize Correa Araujo, Universidade Tuiuti do Paraná, Brasil Edilson Cazeloto, Universidade Paulista, Brasil Eduardo Peñuela Cañizal, Universidade Paulista, Brasil Eduardo Vicente, Universidade de São Paulo, Brasi Eneus Trindade, Universidade de São Paulo, Brasil Erick Felinto de Oliveira, Universidade do Estado do Rio de Janeiro, Brasil Florence Dravet, Universidade Católica de Brasília, Brasil Francisco Eduardo Menezes Martins, Universidade Tuiuti do Paraná, Brasil Gelson Santana, Universidade Anhembi/Morumbi, Brasil Gilson Vieira Monteiro, Universidade Federal do Amazonas, Brasil Gislene da Silva, Universidade Federal de Santa Catarina, Brasi Guillermo Orozco Gómez, Universidad de Guadalajara Gustavo Daudt Fischer, Universidade do Vale do Rio dos Sinos, Brasil Hector Ospina, Universidad de Manizales, Colômbia Herom Vargas, Universidade Municipal de São Caetano do Sul, Brasil leda Tucherman, Universidade Federal do Rio de Janeiro, Brasil Inês Vitorino, Universidade Federal do Ceará, Brasil Janice Caiafa, Universidade Federal do Rio de Janeiro, Brasil Jay David Bolter, Georgia Institute of Technology Jeder Silveira Janotti Junior, Universidade Federal de Pernambuco, Brasil João Freire Filho, Universidade Federal do Rio de Janeiro, Brasil
John DH Downing, University of Texas at Austin, Estados Unidos José Afonso da Silva Junior, Universidade Federal de Pernambuco, Brasil José Carlos Rodrigues, Pontifícia Universidade Católica do Rio de Janeiro, Brasil José Luiz Aidar Prado, Pontifícia Universidade Católica de São Paulo, Brasil José Luiz Warren Jardim Gomes Braga, Universidade do Vale do Rio dos Sinos, Brasi Juremir Machado da Silva, Pontifícia Universidade Católica do Rio Grande do Sul, Brasil Laan Mendes Barros, Universidade Metodista de São Paulo, Brasil Lance Strate, Fordham University, USA, Estados Unidos Lorraine Leu, University of Bristol, Grã-Bretanha Lucia Leão, Pontifícia Universidade Católica de São Paulo, Brasil Luciana Panke, Universidade Federal do Paraná, Brasil Luiz Claudio Martino, Universidade de Brasília, Brasil Malena Segura Contrera, Universidade Paulista, Brasil Márcio de Vasconcellos Serelle, Pontifícia Universidade Católica de Minas Gerais, Brasi Maria Aparecida Baccega, Universidade de São Paulo e Escola Superior de Propaganda e Marketing, Brasil

Maria das Graças Pinto Coelho, Universidade Federal do Rio Grande do Norte, Brasil Maria Immacolata Vassallo de Lopes, Universidade de São Paulo, Brasil Maria Luiza Martins de Mendonça, Universidade Federal de Goiás, Brasil Mauro de Souza Ventura, Universidade Estadual Paulista, Brasil Mauro Pereira Porto, Tulane University, Estados Unidos Nilda Aparecida Jacks, Universidade Federal do Rio Grande do Sul, Brasil Paulo Roberto Gibaldi Vaz, Universidade Federal do Rio de Janeiro, Brasil Potiguara Mendes Silveira Jr, Universidade Federal de Juiz de Fora, Brasil Renato Cordeiro Gomes, Pontifícia Universidade Católica do Rio de Janeiro, Brasi Robert K Logan, University of Toronto, Canadá

Ronaldo George Helal, Universidade do Estado do Rio de Janeiro, Brasil Rosana de Lima Soares, Universidade de São Paulo, Brasil Rose Melo Rocha, Escola Superior de Propaganda e Marketing, Brasil Rossana Reguillo, Instituto de Estudos Superiores do Ocidente, Mexico Rousiley Celi Moreira Maia, Universidade Federal de Minas Gerais, Brasil Sebastião Carlos de Morais Squirra, Universidade Metodista de São Paulo, Brasil Sebastião Guilherme Albano da Costa, Universidade Federal do Rio Grande do Norte, Brasil

Simone Maria Andrade Pereira de Sá, Universidade Federal Fluminense, Brasil Tiago Quiroga Fausto Neto, Universidade de Brasília, Brasil Suzete Venturelli, Universidade de Brasilia, Brasil

Valério Cruz Brittos, Universidade do Vale do Rio dos Sinos, Brasil Valerio Fuenzalida Fernández, Puc-Chile, Chile Veneza Mayora Ronsini, Universidade Federal de Santa Maria, Brasil Vera Regina Veiga França, Universidade Federal de Minas Gerais, Brasil

\section{COMISSÃO EDITORIAL}

Adriana Braga I Pontifícia Universidade Católica do Rio de Janeiro, Brasil Felipe Costa Trotta I Universidade Federal de Pernambuco, Brasil CONSULTORES AD HOC

Édison Gastaldo I Universidade Federal Rural do Rio de Janeiro, Brasil Gisela Grangeiro da Silva Castro, Escola Superior de Propaganda e Marketing, Brasil Helio Kuramoto, Instituto Brasileiro de Informação em Ciência e Tecnologia, Brasil Juliano Maurício de Carvalho, Universidade Estadual Paulista, Brasil Maria Helena Weber, Universidade Federal do Rio Grande do Sul, Brasi Paulo Carneiro da Cunha Filho, Universidade Federal de Pernambuco, Brasil Vera Regina Veiga França, Universidade Federal de Minas Gerais, Brasil EDIÇÃO DE TEXTO E RESUMOS I Susane Barros SECRETÁRIA EXECUTIVA I Juliana Depiné EDITORAÇ̃̃o ELETRÔNICA I Roka Estúdio
COMPóS I www.compos.org.br

Associação Nacional dos Programas de Pós-Graduação em Comunicação

Presidente

Itania Maria Mota Gomes

Universidade Federal da Bahia, Brasil

itania@ufba.br

Vice-presidente

Julio Pinto

Pontifícia Universidade Católica de Minas Gerais, Brasil juliopinto@pucminas.br

Secretária-Geral

Ana Carolina Escosteguy

Pontifícia Universidade Católica do Rio Grande do Sul, Brasil carolad@pucrs.br 